\title{
Editorials
}

\section{The citizen and the role of taxation}

\author{
Helmut Becker, Deloitte \& Touche, Düsseldorf
}

\section{Contemplations based on the proposed US Regulations on Transfer Pricing}

On 24 January 1992, the U.S. tax authorities published new proposed Regulations on transfer pricing. The draft Regulations provide on page 11 a summary which outlines the methods and considerations to be taken into account in determining an arm's length price for intangible property. The summary refers to Section 1.482-2(d)(2)(iii) of the Regulations which provides in greater detail the methods and the priority in which those methods are applied in determining an arm's length price with regard to intangibles.

The so-called matching transaction method ranks in priority above all the other methods utilized by the Internal Revenue Service. The second method which is applied is the comparable adjustable transaction method and final priority is given to the comparable profit method. All methods are 'depending upon which method relies on the most complete and accurate data and requires the fewest and most readily quantifiable adjustments'. In addition with regard to tangibles, the same rules apply [Section 1.482-2(e)(1)(ii)].

This scale of priorities and its reasons as drafted in the proposed Regulations has caused this author to contemplate about the citizen and the role of taxation. The starting point of this analysis is the essence of taxation.

Private property and individual autonomy are predominant in a free and democratic world. Interference can occur through social or public liability if citizens have decided to live in the community of a state. Taxation is the direct result of such social or public liability, and therefore constitutes an exemption or restriction of the basic principles of private property and individual autonomy. Thus, tax law is intervention law and must always be justified by the need for social and/or public integration of a citizen into the State. If there exist doubts, priority is always given to the citizen, his private property and his individual autonomy.

If one bears this basic principle in mind and takes into consideration the proposed US regulations, then the starting point must be the actual choice of the entrepreneur. Although the entrepreneur's choice is based on individual autonomy, this choice must be balanced against social or public liability and must not represent a misuse.

In order to determine whether this restriction meets the above test, it must be assessed on the basis of its objective criteria and not as to whether it is suitable or practicable. The method chosen by the entrepreneur is as such decisive and his choice should be respected irrespective of the fact whether it may be easy or difficult to examine, whether scarce or voluminous data is available and whether an examination may be laborious or troublesome. If a laborious method is chosen, the tax authorities will have to accept it since the State exists on behalf of the citizen and not the citizen on behalf of the State. Only after reasonable diligence in which the citizen has to participate in determining whether the chosen pricing method should be approved, may another method be chosen. At this juncture, practicality become significant. Nonetheless, an effort must be made to remain as close as possible to the pricing method initially chosen by the entrepreneur.

These basic considerations are not reflected in the proposed US pricing Regulations. The priority scale regarding the pricing methods along with numerous other specific Regulations makes life easier for the US tax authorities at the expense of citizens. From their own point of view this may be understandable, however, they should take care not to return to the authoritative State against which they rebelled when they created their state. Despite the above, the international community of tax experts has little empathy with the US authorities in undertaking labour savings to the detriment of the taxpayer. 